\title{
OPPORTUNITIES AND CHALLENGES OF LITTLE RUAHA RIVER TO THE LOCAL COMMUNITY'S LIVELIHOODS IN IRINGA MUNICIPAL, TANZANIA
}

\author{
Gabriel K. Ndimbo ${ }^{1}$ Helena E. Myeya ${ }^{2}$ and Lucy Kassian ${ }^{3}$ \\ 'Department of History, Political Science and Development Studies, \\ Mkwawa University College of Education, University of Dar es Salaam, Tanzania \\ ${ }^{2}$ Department of Geography and Economics, \\ Mkwawa University College of Education, University of Dar es Salaam, Tanzania \\ ${ }^{3}$ Department of Geography and Economics, \\ Mkwawa University College of Education, University of Dar es Salaam, Tanzania \\ Correspondence Author Email. myeyahelena@yahoo.com
}

\begin{abstract}
This paper examines opportunities and challenges of Little Ruaha River on people's livelihoods in Iringa Municipal, Tanzania. A total of 105 respondents from Ruaha ward and 10 key informants were involved in this study. The study employed quantitative and qualitative approaches in collecting and analyzing data. Questionnaire survey, interviews, field observations and documentary review were used as data collection techniques. Quantitative data were analyzed using descriptive statistics while qualitative data were analyzed using content analysis. The study findings reveal that Little Ruaha River is very potential to the adjacent community as it supports small scale agriculture, brick making, small scale industries, domestic uses and fishing. Though the river is very potential, full utilization of water resource is hindered by river fluctuation, improper human activities, water use restrictions, floods, existence of dangerous animals and lack of capital. The study concludes that, the river is very potential to the local community, thus recommending sustainable exploitation of water resource for improved livelihood and resource conservation.
\end{abstract}

Key words: Challenges, Livelihoods, Little Ruaha River, Opportunities

\section{Introduction}

Rivers are essential for life and well-being of the people and ecosystem around the globe. Rivers around the world supplies water for various activities ranging from domestic to industrial uses (Mwakalila, 2014; Kashaigili et al., 2007). Various studies including International Labour Organisation (ILO), (2019), Adu et al. (2017), Habiba et al. (2015), Chazovachii (2012), Taele et al. (2012) and Kashaigili et al. (2005) report on the importance of rivers on employment creation through agriculture and fishing. Potentials of rivers have been reported in different parts of the world. A study by Habiba et al. (2015) reports on the usefulness of rivers in Bangladesh where fishing employs more than 167,000 fishermen and also acts as a source of water to livestock keepers. Additionally, Morton and Olson (2018) admit that, Mekong river which is shared by six South East Asian countries is a heart of more than 190 million people who depend on various river resources for their survival. Furthermore, it is reported that rivers are helpful in generating hydroelectric power which is very important for fostering economic development (Avila et al., 2017; Mwakalila, 2011; Kashaigili, 2007; Ngereza, 2005). Like other countries, Tanzania is endowed with various river systems across the country. The southern part of the country is very potential for water resources in which the Great Ruaha River (GRR) and the Little Ruaha River (LRR) are 
found (McClain et al., 2013). The GRR is the largest river in the southern part of the country and while LRR is one of its tributary (Mwakalila, 2014).

Both the GRR and LRR are very potential for economic development in Tanzania. The Mtera Reservoir which is very important for hydroelectric power generation in Tanzania is contributed by 56 percent of GRR, 26 percent of Kisigo river and 18 percent of LRR (Kashaigili et al., 2007). The communities along the GRR and LRR all depend on land, water and forest resources to live and produce goods (Mwakalila, 2014; Kashaigili et al., 2005). Moreover, these rivers act as a lifeline of the Ruaha national park and its ecosystem (Mwakalila, 2014; Kashaigili et al., 2007).

Despite of the reported river potentials in various countries of the world, full utilization of river resources is encountered by a number of challenges. Climatic changes and drying up of water sources is the mostly notable challenge towards achieving maximum utilization of rivers. A study by Kassian et al. (2017) noted effects of climate change on river water flow in Tanzania which affected activities conducted along the river system. In addition to that, Avila et al. (2017) observed that, reliability of hydroelectric power in subSaharan Africa was highly affected by climate change of which erratic rainfall patterns and long term drought in some areas was reported to reduce the intended output of generated hydroelectric power.

In Tanzania, population growth has been reported to increase the demand for land which has resulted to high deforestation along water sources thus negatively affecting river systems (Kassian et al., 2017; Mwakalila, 2014). Not only that, but also population increase has triggered over utilization of water resource through increased irrigation activities thus affect river water flow. Furthermore, poor agricultural practices along river catchments particularly, applications of toxic fertilizers and over cultivation along the river valleys have also been reported to trigger the deterioration of water quality and quantity in rivers (URT, 2012).

Although various studies (Kassian et al., 2017; Mwakalila, 2014; Mwakalila, 2011; Kangalawe et al., 2011; Kashaigili et al., 2007; Kashaigili et al., 2005 and Ngereza, 2005) have been conducted to examine the importance of rivers and water resources on the people's livelihood in Tanzania, little is reported on the usefulness of the LRR to the local community of Ruaha ward in Iringa Municipal, which created a particular concern for conducting this study. This study therefore intends to identify the usefulness of LRR on people's livelihood and examine challenges facing the local community in accessing potentials of LRR. The findings from this particular study add to the existing body of knowledge on potentials of rivers to the local community and challenges which face local communities in harnessing benefits of water resources. Challenges identification helps the government in setting policies which are friendly to both community members and for environmental conservation.

\section{MATERIAL AND METHODS \\ The Study Area}

This study was carried out in Iringa Municipal, Tanzania (Figure 01). Iringa Municipal lies between latitude $7^{0} 50^{\prime}$ South and longitude $35^{\circ} 45^{\prime}$ East. It covers an area of 176.987 square kilometers. Administratively, the Municipal has 16 wards namely Ruaha, Kihesa, Mkwawa, Kitwiru, Mtwivila, Mwangata, Isakalilo, Makorongoni, Nduli, Ilala, Kitanzini, Mlandege, Kwakilosa, Gangilonga, Mivinjeni and Mshindo (URT, 2013b; URT, 2011). This particular study was conducted at Ruaha ward (Figure 01). Ruaha ward lies between latitude $7^{0} 43^{\prime}$ South and longitude $35^{\circ} 42^{\prime}$ East. According to the 2012 census report, the ward had a total population of 16,984 people with 9066 males and 7918 females (URT, 2013a). The ward occupies an area of about 61.33 square kilometers (URT, 2013b). 


\section{Drainage and Soil System}

The drainage pattern of Iringa Municipal comprises rivers, streams and springs. LRR is the main river running through Iringa town covering 17 kilometers across the Municipal (URT, 2014). The drainage system is also characterized by springs including Kitwiru and Mawelele and seasonal streams namely Hoho, Kigonzile, Kitasengwa, Mwangata, Kibwabwa and Itamba which flows to and from different directions. The geology of the area comprises of hard rock characterized by loam, sandy loam and alluvium soils ( URT, 2011). The soils in the Municipal are very fertile thus being suitable for growing varieties of both cash and food crops.

\section{Economic Activities}

The population of Iringa urban is involved in agricultural activities, wage employment, industrial activities and trading. Urban farming (crop and livestock) employs to over 29 percent of the labour force and contributes 40 percent of the food requirements for the Municipal (URT, 2014). The Municipal has a total of 13,300 out of 162,030 (Ha) being suitable for farming. Crops grown are maize, vegetables, sunflowers, beans, soya and potatoes while animals kept include cattle, pigs, sheep, poultry and goats (URT, 2011). Not only that, but also trading and commerce account for 58 percent of income generating sources in the Municipal (URT, 2014). Industrial activities are also conducted in the Municipal characterized by both small and medium scale. Small scale iindustries comprise food processing, tailoring and carpentry units. Medium scale industries include those dealing with fruit processing, ivory sweets and oil production, bakery, dairy production and milling machine (URT, 2011).

Figure 01: The Study Area

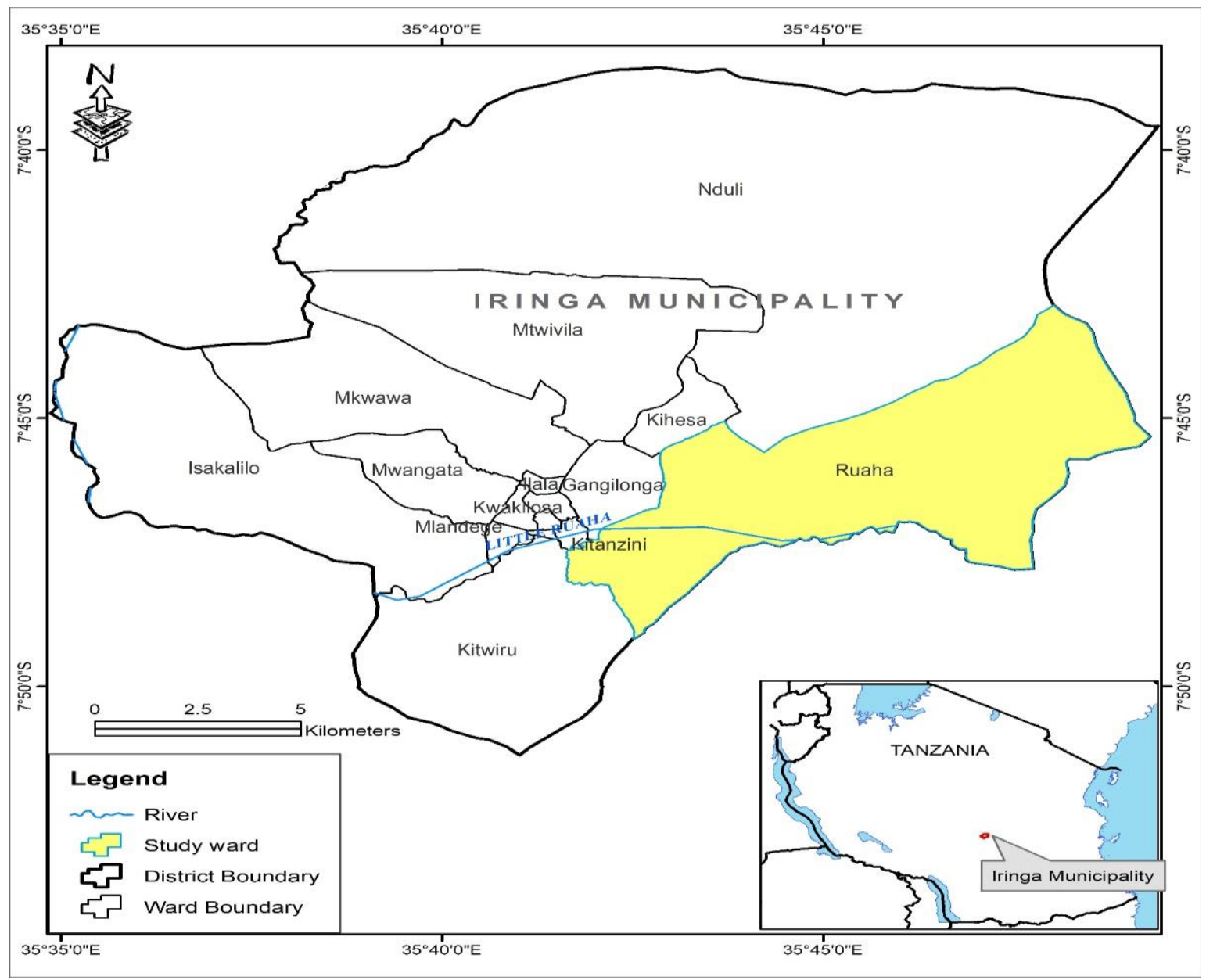




\section{Sampling Techniques}

Both simple and purposive sampling techniques were employed in selecting the study area and participants. Ruaha ward was purposively selected because it is among the areas where LRR crosses in large part thus being potential to the local community. Thereafter simple random sampling technique was used to select 105 respondents (8.5 percent) of 1235 people who were reported by government leaders to benefit either directly or indirectly from the LRR. The chosen sample size was more than 5 percent recommended by Boyd et al. (1972) thus being representative. Additionally, purposive sampling technique was employed in the selection of key informants who were involved in in-depth interviews and Focus Group Discussions (FGDs).

\section{Methods of Data Collection and Analysis}

Questionnaire survey administration, interviews, field observation and documentary review were employed as data collection techniques. The study involved a total of 105 respondents for questionnaire survey and 10 participants for in-depth interviews and FGDs. Both closed and open ended questions were used in collecting information about the potentials and challenges of LRR. One FGD (08 participants both males and females) was held. The group comprised people who were practising small scale agriculture and small scale industrial workers. In-depth interviews were conducted to 2 participants who were government officials. Information from in depth interviews and FGD helped to supplement the missing data from questionnaire survey. Data obtained through questionnaire survey were coded and analyzed by using Statistical Package for Social Sciences (SPSS) and Microsoft Excel software to generate descriptive statistics. Qualitative data collected through interviews and FGDs were coded and arranged according to research themes through content analysis.

\section{RESULTS AND DISCUSSION \\ Demographic Characteristics of Respondents}

Findings from this study (Table 1) revealed that, 28.9 percent of respondents were aged between 20 to 29 years, 27.5 percent were between 30 to 39 years, 21.5 percent were aged between 40 to 49 years, 16.5 percent were above 50 years and the remaining 5.6 percent were ranging between 10 to 19 years old. Moreover, an examination on sex indicates that, 56.7 percent of respondents were females and the remaining (43.3 percent) were males.

Table 01: Demographic Characteristics of Respondents

\begin{tabular}{|lc|}
\hline Variable & Percentage $\mathbf{N}=\mathbf{1 0 5})$ \\
\hline Age & \\
\hline $10-19$ & 5.6 \\
\hline $20-29$ & 28.9 \\
\hline $30-39$ & 27.5 \\
\hline $40-49$ & 21.5 \\
\hline $50+$ & 16.5 \\
\hline Sex & \\
\hline Female & 56.7 \\
\hline Male & 43.3 \\
\hline Education \\
\hline No formal education & 12 \\
\hline Primary & 47 \\
\hline Secondary & 31 \\
\hline Tertiary & 10 \\
\hline
\end{tabular}


Results further show that, 47 percent of respondents had primary education, 31 percent had secondary education, 12 percent had no formal education and the remaining 10 percent had tertiary education. Age, sex and education levels have implication on livelihood strategies to an individual. There is variation on activities involved between adult and young as well as between females and males. The current results imply that most of the respondents were young and female who were found to engage in livelihood strategies along the LRR, therefore they benefit more than other groups.

Education levels have also high influence on livelihood strategies. Higher education levels enable people to get formal employment while lower levels restrict people from formal employment. Therefore, majority of respondents in the study area were having low education levels which limited them from accessing formal employment thus depended on the river potentials for their livelihood strategies. These findings resemble with what is reported by Kinuthia et al. (2018) and Mulungu and Myeya (2018) who noted the influence of age, sex and education on livelihood strategies.

\section{Potentials of the LRR to the Local Community}

The study results indicate that 53 percent of respondents (Table 2) were engaging in agriculture. Crops grown include maize, beans, onions, tomatoes and green vegetables. It was further reported that, most of the produced goods are consumed within the Municipal and the rest are transported outside the Municipal. These results are in line with what is reported by Kassian et al. (2017) and Mwakalila (2011) in Tanzania and Chazovachii (2012) in Zimbabwe on potentials of rivers on agricultural activities. Authors emphasize that small scale agriculture through irrigation is a major activity practiced along rivers in Tanzania and Zimbabwe.

Nevertheless, livestock keeping was also reported to be practiced in the study area. Respondents reported to keep cattle, goats, sheep, pigs and poultry. The kept animals were reported by respondents to be very beneficial to livestock owners in terms of milk, meat and manure. It was further noted that livestock owners reported to earn income by selling livestock products to the local community and to dairy industries thus, improve their livelihoods. Additionally, it was noted that livestock owners' offers employment to youth who take care those livestock thus act as a source of income for their survival.

Table 02: Potentials of the LRR to the Local Community

\begin{tabular}{|lc|}
\hline Uses & Percentage (N=105) \\
\hline Agriculture & 53 \\
\hline Brick making & 17 \\
\hline Domestic activities & 13 \\
\hline Industrial and garage activities & 12 \\
\hline Gardening & 03 \\
\hline Fishing & 02 \\
\hline
\end{tabular}

Apart from agricultural activities, 17 percent of respondents reported to engage in brick making. This activity was reported to be done mostly by men as compared to women. Brick making is done during dry season because of the nature of activity conducted (Mud bricks) which needs more sun energy as opposed to rain. It was further reported that building construction done in Iringa Municipal depend on those bricks hence act as a source of income to all people who are directly or indirectly involved in this particular activity. Similar results were reported by Kashaigili et al. (2005) and URT (2014) who noted brick making as one among the livelihood strategy conducted along the GRR and LRR. 
Moreover, domestic use particularly drinking, bathing, washing clothes, washing dishes and toilet use were mentioned by 13 percent of respondents to be the other potentials of LRR. The surveyed population reported to depend on water from LRR for their daily activities. These results are in line with findings by Mwakalila (2013) and Kangalawe et al. (2011) who reported domestic use to be among the importance of rivers in southern highlands of Tanzania.

Industrial and garage activities were also reported by 12 percent of respondents. Through in-depth interviews, it was noted that motor vehicle wash and sunflower oil production industries are practiced along the LRR. During FGD, participants admitted to get full benefits from the river as reported hereunder:

"We depend on water from the river for cooling machine and car wash. No any cost is incurred in using the river water as it is easily accessible and utilized...." (Male, aged 34 years.)

Furthermore, gardening was reported by 3 percent of respondents as one of the activity conducted along the LRR. Respondents reported that, within their gardens they grow tree nurseries and flowers. It was further reported that, trees and flowers grown are sold within and outside the Municipal thus help the local community to earn income and participate in environmental conservation. These results concur with that of Habiba et al. (2015) in Bangladesh and Kashaigili et al. (2007) in Tanzania who reports on the importance of rivers on employment creation.

The remaining 2 percent of respondents reported to benefit from the river by engaging in fishing activities which enabled them to get fish for family consumption. These findings are in line with that of Mwakalila (2014) of Tanzania who reported on the usefulness of rivers for fishing activities. These findings also tally with what is reported by URT (2014) on the importance of LRR on fishing though it is not in large scale.

\section{Challenges Hindering Proper Utilization of the LRR}

Results in Table 3 indicate seasonal fluctuation of the LRR was reported by 36 percent of the respondents as a major challenge. Water volume fluctuation was linked with climate change which is associated with reduced rainfall thus having negative effects on water flow. Water fluctuation was reported to affect quality and quantity of crops grown along the river. Through discussion, it was noted that during the dry season, water use conflicts increases due to high demand of water as compared to the supply. Water distribution had negative impact on grown crops as it affected the output which also affected income levels. These results concur with findings by Kassian et al. (2017) who noted increased conflicts and misunderstandings over the access and use of water during the dry season in Iringa rural district.

Table 03: Challenges Hindering Proper Utilization of the LRR

\begin{tabular}{|lc|}
\hline Challenges & Percentage $(\mathbf{N}=105)$ \\
\hline Water fluctuation & 36 \\
\hline Water use restrictions & 24 \\
\hline Improper human activities & 22 \\
\hline Flooding & 10 \\
\hline Lack of capital & 08 \\
\hline
\end{tabular}

Moreover, 24 percent of respondents reported on the existence of government laws and regulations that hinder effective utilization of water in the LRR. Through discussion with participants and literature review it was noted that the National water policy of 2002 and water resource management act of 2009 are the main documents used in guiding the use and management of water resources in Tanzania, LRR being in particular. It was noted 
that, implementation of national water policy and acts restrict human activities to be conducted near the water channel. These water use regulations advocates on sustainable use of water resources but seems to be unfriendly to people's livelihoods, therefore, their existence makes life difficulty. These results tally with findings by Kashaigili et al. (2005) who noted water use allocation challenges in the Great Ruaha River catchment in Tanzania.

Furthermore, improper farming methods and water pollution were reported by 22 percent of the respondents to be among the challenges on water resource utilization particularly on domestic use. Respondents argued that, people are not much faithful in adhering to rules and regulations introduced by the government authorities on proper use of water resource. Through agriculture, pesticides and insectides are highly applied for output maximization. Application of these chemicals was reported to have negative effect on water quality and human health. Additionally, industries produce chemicals which are directed to water sources thus contribute to water pollution. The current results are in line with what is reported by Avila et al. (2017) and Kashaigili et al. (2007) who also noted human activities to affect the quality and quantity of water resources.

The study further noted that 10 percent of respondents reported flooding to be among the challenges hindering full utilization of river potentials. Respondents further reported that during the rainy season particularly in years with high rainfall, the water volume increases causing floods that destroy crops, gardens and sometimes cause deaths for both human being and animals. This was also reported by one participant during indepth interview:

"The river is dangerous to human being and crops especially during the rainy season. During years of high rainfall, human, livestock and crops are highly affected"... (Female, aged 39 years).

The current results on effects of flooding are in line with what is reported by Talbot et al. (2018) and Milojevic et al. (2012) who noted that flooding and wet weather are closetful to agricultural land as they cause reduction of crop harvest and effects on the ecosystem.

Apart from flooding, 8 percent of respondents reported lack of capital to be among the challenges in utilizing potentials of LRR. Through discussion, it was noted that some respondents desired to establish income generating activities like crop and vegetable cultivation along the river but they were unable due to financial constraints as it is reported hereunder:

"Engaging in agricultural activities along the river Ruaha is beneficial and I wish to conduct green vegetable farming but I don't have capital for starting this activity".(Male, aged 32) years.

The results of this particular study concur with what is reported by Mulungu and Myeya (2018) who noted lack of capital to be among the challenges for intensive utilization of natural resources among community members in southern highlands of Tanzania.

\section{Conclusion and Recommendations}

This paper has examined opportunities and challenges of LRR on people's livelihoods in Iringa Municipal, Tanzania. The study findings revealed that LRR is very potential to the adjacent community as it supports existence of small scale agriculture, small scale industries, domestic uses and fishing activities. Results further revealed that river fluctuation, water use laws and restrictions, improper human activities and flooding were among the reported challenges on full utilization of water resource. The study concludes that LRR is potential to the local community calling for sustainable utilization of water system for the benefits of the local community and resources conservation. Community 
members should be educated on the need to follow rules and regulations on water resource use and management in order to achieve sustainable development.

\section{References}

1. Adu, D., Zhang, J. Fang, Y., Suoming, L. \& Darko, R.O. (2017). A Case study of status and potential of small hydropower plants in Southern African Development Community Energy Procedia, 141, pp. 352-359.

2. Avila, N., Carvallo, J. P., Shaw, B. \& Kammen, D. M. (2017). The energy challenge in sub-Saharan Africa: A guide for advocates and policy makers: Part. Generating energy for sustainable and equitable development. Oxfam Research Backgrounder series. https://www.oxfamamerica.org/static/media/files/oxfam-RAEL-energySSA-pt1.pdf accessed on 13.05.2020.

3. Boyd, H. W., Westfall, R., \& Stasch, S. F. (1972). Marketing research: text and cases. RD Irwin.

4. Chazovachii, B. (2012). The Impact of Small Scale Irrigation Schemes on Rural Livelihoods: The Case of Pangani Irrigation Scheme, Bikita District Zimbabwe, Journal of Sustainable Development in Africa, 14 (4) pp. 217-231.

5. Habiba, U., Abedin, M.A., Hassan, A.W.R. \& Shaw, R. eds., (2015). Food security and risk reduction in Bangladesh. Springer Japan.

6. International Labor Organization-ILO (2019). Portfolio of policy guidance notes on the promotion of decent work in the rural economy: Water for Improved Rural Livelihoods. Available at https://www.https://www.ilo.org/global/topics/economic-and-socialdevelopment/rural development/WCMS_436223/lang--en/index.htm accessed on 13.05.2020.

7. Kassian, L. M., Tenywa, M., Liwenga, E. T., Dyer, K. W., \& Bamutaze, Y. (2017). Implication of climate change and variability on stream flow in Iringa region, Tanzania. Journal of Water and Climate Change, 8(2), pp. 336-347.

8. Kashaigili, J. J., Mccartney, M., \& Mahoo, H. F. (2007). Estimation of environmental flows in the Great Ruaha River catchment, Tanzania. Physics and Chemistry of the Earth, Parts A/B/C, 32(15-18), pp. 1007-1014.

9. Kashaigili, J. J., Kadigi, R. M., Lankford, B. A., Mahoo, H. F., \& Mashauri, D. A. (2005). Environmental flows allocation in river basins: Exploring allocation challenges and options in the Great Ruaha River catchment in Tanzania. Physics and Chemistry of the Earth, Parts A/B/C, 30(11-16), 689-697.

10. Kangalawe, L, Mwakalila, S \& Masolwa, P (2011). Climate Change Impacts, Local Knowledge and Coping Strategies in the Great Ruaha River Catchment Area, Tanzania, Journal of Natural Resources, 2 (4). pp. 212-223.

11. Kinuthia, K. J., Inot, S. K., \& Nakhone, L. (2018). Factors influencing farmer's choice of crop production response strategies to climate change and variability in Narok East sub-county, Kenya. Journal of Natural Resources and Development, 8, 69-77.

12. McClain, M. E., Kashaigili, J. J., \& Ndomba, P. (2013). Environmental flow assessment as a tool for achieving environmental objectives of African water policy, with examples from East Africa. International Journal of Water Resources Development, 29 (4), 650665.

13. Milojevic, A., Armstrong, B., Hashizume, M., McAllister, K., Faruque, A., Yunus, M., Streatfield, P.K., Moji, K., \& Wilkinson, P. (2012). Health effects of flooding in rural Bangladesh. Journal of Epidemiology, 23 (1), pp. 107-115.

14. Morton, L.W. and Olson, K.R. (2018). The Pulses of the Mekong River Basin: Rivers and the Livelihoods of Farmers and Fishers, Journal of Environmental Protection, 9 (4) pp. 431-459. https://doi.org/10.4236/jep.2018.94027 accessed on 11.06.2020.

15. Mulungu $C, A$ and Myeya $H, E(2018)$. Survival strategies and livelihood diversification of Ileje Migrants in Mbozi District, Southern Tanzania, Journal of African Studies and Development, 10 (4), pp. 43-50. 
16. Mwakalila, S. (2014). Climate Variability, Impacts and Adaptation Strategies: The Case of Mbeya and Makete Districts in Great Ruaha Catchment in Tanzania, Journal of Water Resource and Protection, 6 (1), pp. 43-48.

17. Mwakalila, S. (2013). Integrated water resource management as climate change adaptation strategy in the Great Ruaha river catchment of Tanzania, Journal of Environmental Science and Water Resources, 2(11), pp. $396-402$.

18. Mwakalila, S. (2011). Vulnerability of People's Livelihoods to Water Resources Availability in Semi-Arid Areas of Tanzania. Journal of Water Resource and Protection, 2011, 3, 678-685 doi:10.4236/jwarp.2011.39078 accessed on 23.09.2019.

19. Ngereza, A., (2005). Water and Environment in Tanzania: A Case of Pangani River Basin. Proceedings of Topics of integrated watershed management, 3.

20. Taele, B.M., Mokhutšoane, L.\& Hapazari, I., (2012). An overview of small hydropower development in Lesotho: Challenges and prospects. Renewable Energy, 44, pp.448452.

21. Talbot, C.J., Bennett, E.M., Cassell, K., Hanes, D.M., Minor, E.C., Paerl, H., Raymond, P.A., Vargas, R., Vidon, P.G., Wollheim, W. \& Xenopoulos, M.A., (2018). The impact of flooding on aquatic ecosystem services. Biogeochemistry, 141 (3), pp. 439 - 461. https://doi.org/10.1007/s10533-018-0449-7 accessed on 18.07.2020.

22. United Republic of Tanzania (URT) (2014). Iringa master plan 2015 - 2035. Dar es Salaam, Tanzania.

23. United Republic of Tanzania (URT) (2013a). Tanzania census report. Dar es Salaam, Tanzania.

24. United Republic of Tanzania (URT) (2013b). Iringa region socio-economic profile. Dar es Salaam, Tanzania.

25. United Republic of Tanzania (URT) (2011). Iringa Municipal social and economic profile. Dar es Salaam, Tanzania. 